\title{
Current Concepts on the Pathogenesis of Peri-implantitis: A Narrative Review
}

\author{
Ioannis Fragkioudakis ${ }^{1, \odot}$ Georgia Tseleki ${ }^{1} \quad$ Aikaterini-Elisavet Doufexi ${ }^{1} \quad$ Dimitra Sakellari ${ }^{1}$ \\ ${ }^{1}$ Department of Preventive Dentistry, Periodontology and Implant \\ Biology, Dental School, Aristotle University of Thessaloniki, \\ Thessaloniki, Greece \\ Address for correspondence loannis Fragkioudakis, Department \\ of Preventive Dentistry, Periodontology and Implant Biology, Dental \\ School, Aristotle University of Thessaloniki, Thessaloniki, Greece \\ (e-mail: ifragkio@gmail.com).
}

Eur J Dent 2021;15:379-387

\begin{abstract}
As implant treatment has been integrated in contemporary dental practice, complications with the forms of peri-implant mucositis and peri-implantitis have also increased in prevalence. Peri-implantitis is the more severe biological complication and is defined as an inflammatory disease affecting peri-implant tissues resulting in bone and eventually implant loss. In addition, the treatment of peri-implantitis has currently become a substantial global economic burden. In the current study, a search was conducted in several electronic databases using specific keywords relevant to the article's main topic. An increasing number of scientific reports have investigated the etiopathology of peri-implant diseases, focusing mainly on peri-implantitis. Microbial biofilm consists an important etiological factor of peri-implant pathology analogous to periodontal diseases. Although several data confirm that peri-implant infections are dominated by gram-negative bacteria, similar to periodontal infections, there is evidence that some cases may harbor a distinct microbiota, including opportunistic microorganisms and/ or uncultivable species. Additionally, data support that several parameters, such as genetic predisposition of individual patients, occlusal overload, and local factors such as titanium particles and excess cement, may be implicated in peri-implantitis pathogenesis. Simultaneously, the release of titanium metal particles and their biological consequences or the presence of excess cement in the adjacent peri-implant tissues

Keywords

- peri-implantitis

- foreign body

- risk factors have also been suggested as factors that contribute to peri-implant pathology. A specific line of research also indicates the role of foreign body response to implant installation. This narrative review aims to discuss the current concepts of etiopathogenetic factors implicated in peri-implantitis.
\end{abstract}

\section{Introduction}

Implant dentistry has successfully been integrated into modern dentistry during the past 30 years. It is postulated that 450,000 implants are installed annually in the United States, aiding patients' oral rehabilitation. ${ }^{1}$ However, complications are not rare. Today's dental clinicians face the burden of peri-implantitis resulting in marginal bone loss (MBL) and eventually implant failure.

The term "peri-implantitis" was first introduced in the first European Workshop on Periodontology in 1994. Since then, numerous definitions have been proposed to describe the bone loss that characterizes the aftermath of implant
DOI https://doi.org/ $10.1055 / \mathrm{s}-0040-1721903$ ISSN 1305-7456. (c) 2021. European Journal of Dentistry.

This is an open access article published by Thieme under the terms of the Creative Commons Attribution-NonDerivative-NonCommercial-License, permitting copying and reproduction so long as the original work is given appropriate credit. Contents may not be used for commercial purposes, or adapted, remixed, transformed or built upon. (https://creativecommons.org/licenses/by-nc-nd/4.0/)

Thieme Medical and Scientific Publishers Pvt. Ltd., A-12, 2nd Floor, Sector 2, Noida-201301 UP, India 
installation. ${ }^{2,3}$ Currently, peri-implantitis is defined as the pathological condition around dental implants characterized by inflammation in the peri-implant mucosa and progressive bone loss. In contrast, peri-implant mucositis is characterized by inflammation in the implant surrounding mucosa without concomitant bone loss. ${ }^{3}$ The prevalence of peri-implantitis is estimated to be $10 \%$ at the implant level and $20 \%$ at the patient level at 5 to 10 years of function. ${ }^{4}$ However, most studies reveal a prevalence with a wide range (19-65\%). ${ }^{5,6}$ The prevalence of peri-implantitis is dependent on factors such as the population under investigation and the threshold set for disease evaluation. Thus, the global burden of peri-implantitis is difficult to precisely evaluate. ${ }^{7}$ Nonsurgical therapy, with the aid of different decontamination methods, has been mainly used to treat mild peri-implant lesions; however, in most cases, surgical treatment is mandatory to confront severe peri-implant infections. ${ }^{8}$ Besides, regenerative peri-implant treatment, though promising, does not guarantee the success of the infected implant. ${ }^{9}$ Peri-implantitis has currently become a substantial economic burden since implant therapy was estimated at the cost of US $\$ 2.91$ billion in $2016 .{ }^{10}$ Moreover, the number of studies regarding peri-implantitis in PubMed has risen in the past years from 86 articles in the 1990s to a total of 1,938 articles until $2018 .^{10}$

The consensus report of workgroup 4 of the 2017 World Workshop on the Classification of Periodontal and Peri-Implant Diseases and Conditions concluded that peri-implantitis is an inflammatory process of a microbial origin that causes bone loss. ${ }^{3}$ In addition, several risk factors have been proposed as potential codrivers in this entity, including history of periodontitis and poor plaque control. ${ }^{11}$ Factors such as occlusal trauma and titanium particles have also been indicated as potential risk factors with a low level of evidence. ${ }^{11}$ The microbial involvement in peri-implantitis initiation and progression has been established. ${ }^{12}$ In parallel with periodontitis, where the loss of supporting tissues occurs due to microbial infection, peri-implantitis is considered by some a disease with many similarities to periodontitis. ${ }^{13}$ However, recent studies suggest that peri-implantitis may be a distinct condition or even result from a foreign body reaction (FBR), emphasizing the role of the host response in the disease initiation. ${ }^{14}$

The scope of this narrative review is to describe the current concepts on the pathogenesis and progression of peri-implantitis, based on contemporary literature. The review will only include studies referring to titanium implants as the literature contains scarce reports of peri-implantitis in zirconia implants.

\section{Materials and Methods}

The present narrative review aims to discuss scientific information on the etiology and pathogenesis of peri-implantitis by reviewing relevant literature. A search was undertaken between October and November 2019 in the PubMed Web site database (U.S. National Library of Medicine, National Institutes of Health; Bethesda, Maryland, United States). Only articles written in English were considered initially. The following keywords were used in the search: "peri-implantitis," "peri-implant mucositis," "peri-implant microbiota," periodontal microbiota," "peri-implantitis pathogenesis," "foreign body reaction," and "peri-implantitis risk factors." Both review articles and research articles considered relevant for discussion were selected and analyzed in detail. All reference lists of the selected articles were then handsearched for additional articles deemed appropriate by two of the authors (I.F. and G.T.). The selection process resulted in choosing 338 articles analyzed in detail, leading to a final inclusion of 107 articles.

\section{Microbiological Implication in Peri-implantitis}

Dental implants were first introduced for the rehabilitation of edentulous patients. As a result, any failures that dentists would encounter at that time were attributed to parameters other than microorganisms, such as excess loading. ${ }^{15}$ Bacterial colonization was later considered as the leading cause of peri-implant diseases. Early animal studies were conducted to evaluate the peri-implant tissue reaction after biofilm formation and observed the resulting establishment of inflammatory lesions. ${ }^{16,17}$ Berglundh et al investigated the effects of plaque formation on teeth and implants in Beagle dogs. The study demonstrated that both peri-implant and periodontal tissues reacted similarly. An inflammatory response was provoked, characterized by an increase of leukocyte transmigration and the establishment of a connective tissue lesion. ${ }^{18}$ In another experiment in Labrador dogs, by Ericsson et al, implants exposed to daily plaque control displayed healthy surrounding tissues. In contrast, this procedure's termination resulted in creating an inflammatory cell infiltrate in the marginal portion of peri-implant mucosa. ${ }^{19}$

Later in the literature, the results of plaque accumulation at implant sites were also examined in human studies. In 1994, Pontoriero et al compared the clinical and microbiological outcomes of experimental gingivitis and peri-implant mucositis in 20 healthy partially edentulous patients. The abolishment of oral hygiene took place for 3 weeks. The study demonstrated no significant differences in all parameters tested and concluded that the development of peri-implant mucositis due to plaque accumulation is similar to the establishment of gingivitis. ${ }^{20}$

Peri-implant diseases are considered analogous to gingivitis and periodontitis, with some differences in the host response. ${ }^{21}$ Many studies have been conducted to compare the microbiological flora of periodontitis and peri-implantitis. The first step for the initiation of bacterial colonization is forming a salivary pellicle consisting of salivary proteins and peptides. When an implant is exposed to the oral cavity, this pellicle forms rapidly on its surface and mediates microorganisms' adhesion. Studies comparing the pellicle formed on teeth and the one on implants found some differences. In specific, salivary pellicles on titanium included high-molecular-weight mucins, salivary $\alpha$-amylase, and proline-rich glycoproteins. Molecules such as low-molecular-weight mucins that are usually found on enamel pellicles were not detected. ${ }^{22}$ In the first year, 
bacterial colonization of implants was believed to resemble that of teeth. The residual teeth were thought to function as niches for periodontal pathogens, which in turn could translocate to implant sites. Consequently, despite the differences that existed between the acquired pellicles, the sequence of biofilm formation was considered identical, ${ }^{23}$ and therefore, teeth and implants were thought to present the same microbial profile ${ }^{24}$ as shown by studies based on culture techniques and molecular ones, such as polymerase chain reaction and deoxyribonucleic acid (DNA)-DNA hybridization.

In 1984, Rams et al used direct phase-contrast microscopy to examine the subgingival microflora of 17 dental implants in humans. In 14 implants considered relatively healthy, with stabilized pockets and no signs of inflammation, higher proportions of nonmotile coccoid cells and low levels of spirochetes were observed. In contrast, implants with deep pockets and inflamed tissues harvested a higher number of spirochetes. ${ }^{25}$ Later, in 1987, Mombelli et al investigated the microbiota of failing and successful implants. They noted that in failing implants, the number of gram-negative microorganisms was elevated, including black-pigmented Bacteroides spp. They suggested that peri-implantitis displays a similar ecosystem to that of periodontal diseases..$^{12}$ In a later study, the microbiota of implants and teeth was characterized in 17 patients who showed signs of peri-implantitis and 19 patients with no signs of inflammation who served as controls. ${ }^{26}$ The method used for microbiological analysis was "checkerboard" DNA-DNA hybridization. The analysis revealed that consensus periodontal pathogens such as Porphyromonas gingivalis, Aggregatibacter actinomycetemcomitans, Prevotella intermedia, Treponema denticola, and Tannerella forsythia were present at all sites. Still, they were extremely elevated at sites with peri-implantitis, indicating a site-specific inflammation. Hence, early reports revealed that implants' microbiological profile in health consists mainly of gram-positive cocci and nonmotile rods, similar to that of teeth with healthy periodontium. Furthermore, in peri-implantitis, the predominance of gram-negative anaerobic species, commonly found in sites with periodontitis, was reported.

Implants and teeth exist in the same environment, the oral cavity, so it seemed rational to present similar microbiota. However, several studies that utilized cultural and molecular methods for identifying microorganisms have shown the presence of some opportunistic bacteria, not associated with periodontal diseases. ${ }^{27-30}$ Leonhardt et al demonstrated in 1999 that yeasts, enteric rods, and Staphylococci spp. were frequently found in peri-implant areas; after evaluating by cultural techniques, the microbiota around implants with inflamed and healthy tissues. ${ }^{27}$ Later studies using culture-independent techniques, such as $16 \mathrm{~S}$ ribosomal ribonucleic acid (rRNA) sequencing, also indicated that peri-implantitis lesions' microbiota is more complicated than previously thought. ${ }^{31}$ In 2012, Kumar et al investigated the peri-implant microbiota in health and disease by analyzing plaque samples from 40 patients using the 16S rRNA pyrosequencing technique. ${ }^{32}$ They concluded that peri-implantitis is a more straightforward but more heterogeneous infection compared with periodontitis. Peri-implant tissues might harbor periodontal bacteria, but the microbiota differs from the subgingival communities observed adjacent to periodontal tissues. ${ }^{29}$ In another investigation, conducted by Albertini et al, the presence of opportunistic flora, such as Staphylococcus aureus, enteric bacteria, Pseudomonas spp., and yeasts, was also assessed. ${ }^{33}$ The results showed a considerable prevalence of these microorganisms, and the authors suggested that bacteria different from periodontal pathogens can be found on implant surfaces. The interesting finding in this study was that in two cases of peri-implantitis, none of the investigated organisms were detected. ${ }^{30}$ The fact that the microbial profile of peri-implantitis might be distinct from that of periodontitis was also suggested by studies applying new technologies, such as metagenomics. ${ }^{34} \mathrm{~A}$ recent study used a different method to identify microbiota in peri-implantitis sites, the matrix-assisted laser desorption/ionization-timeof-flight mass spectrometry. The major habitants that were detected were Neisseria flavescens, Streptococcus constellatus, Slackia exigua, Streptococcus intermedius, Fusobacterium nucleatum, and Gemella morbillorum. It was also emphasized that the distribution of bacteria differed significantly among implants. ${ }^{35}$

Taken collectively, current data confirm that peri-implant infections are dominated by gram-negative bacteria, similar to periodontal infections, but some cases may harbor a distinct microbiota. ${ }^{36-38}$ Although early reports showed similarities between the peri-implant and periodontal flora, later studies demonstrated that peri-implantitis lesions might present consensus periodontal pathogens and opportunistic microorganisms, such as S. aureus, Streptococcus anaerobius, Escherichia coli, Candida, and Streptococci spp. ${ }^{39}$ Furthermore, sequencing methods have also revealed other noncultivable microorganisms associated with peri-implant disease. Asaccharolytic anaerobic gram-positive rods such as Eubacterium nodatum, Eubacterium brachy, S. exigua, Gemella sanguinis, and anaerobic gram-negative rods such as Mitsuokella sp. and Treponema lecithinolyticum have been identified..$^{40}$ The discrepancies among these studies may arise from the different methods used for microbiological processing. ${ }^{41}$ The microbiological profile of peri-implant diseases remains an issue of interest. Many investigations and reviews have been conducted to conclude whether the microbiota is different from periodontitis; however, controversies still exist. The latest studies conclude that there is insufficient evidence to support the distinct microbiota between peri-implant and periodontal diseases. ${ }^{42,43}$

In contrast, others state that they may be different entities in terms of microbiological profile. ${ }^{88}$ Therefore, further studies need to be conducted to define the microbiological profile of peri-implant tissues. Newest technologies, such as shotgun sequencing of the whole genome of bacteria involved in peri-implantitis, would be beneficial for this purpose. Still, no such research has been published up to now. 


\section{Foreign Body Reaction around Implants}

\section{Redefining Osseointegration}

As defined by Branemark in 1977, osseointegration is the structural and functional connection between living bone and the surface of a load-bearing artificial implant. ${ }^{44}$ Though varying over the years, the definition describes osseointegration as a bone apposition phenomenon onto the implant surface, leading to functional ankylosis. ${ }^{45}$ Donath was the first to advocate that osseointegration is an FBR where the tissues aim at embedding the titanium material in the bone as a mode of protection for adjacent tissues. ${ }^{46}$ They claimed that any foreign material placed in the bone would be rejected, dissolved, resorbed, or demarcated with a dense bone layer to protect nearby tissues. ${ }^{47}$ These observations led Albrektsson and Wennerberg to redefine the term osseointegration. In their article in 2013, they proposed that osseointegration constituted an FBR in a state of equilibrium with the host and characterized by mild chronic inflammation ${ }^{14}$ and later concluded that "osseointegration is a FBR where the interfacial bone is formed as a defense reaction to shield off the implant from the tissues." 48 This new definition emphasizes the role of the immune response in the foreign body engulfment. It entails that MBL around dental implants may be a whole different phenomenon rather than a bacterial implicated disease.

\section{Role of the Immune Response}

An acute inflammatory response is elicited at the moment after implant installation. ${ }^{10}$ Complement activation plays a crucial role in the immune response cascade by identifying a foreign body's presence and regulating macrophages monocytes' chemotaxis and bone cells. ${ }^{49}$ Macrophages also play a significant role in the foreign body response. Their specific subtypes (M1 and M2) possess proinflammatory and wound healing properties regulating bone metabolism. ${ }^{50}$ Besides, foreign body giant cells have frequently been found on implant surfaces, possibly due to macrophage fusion, ${ }^{51}$ further supporting the concept of a FBR around dental implants. Recent evidence in an animal model suggests a time-dependent immune response after implant installation, characterized by an upregulation of immune defense cells (e.g., macrophages) during the first 10 days, followed by an upregulation of bone repairing cells and downregulation of osteoclasts in 28 days. $^{52}$ Overall, FBR around implants appears to be a nonspecific immune-driven reaction with complement and macrophages comprising major components of the resulting immune-inflammatory balance. ${ }^{48,53}$

\section{Marginal Bone Loss around Implants-Why Does It Occur?}

Considering osseointegration as a FBR in balance with the host, MBL around implants should consist of the immune-driven loss of this balance. The exact pathogenesis behind bone loss is not clearly understood; however, a hypothetical model suggests several factors, such as cement remnants and titanium particles in the breakdown of the established equilibrium. ${ }^{49}$ As a response to the triggering factor, complement and macrophages become activated and upregulate osteoclastic activities leading to bone loss. ${ }^{49}$ Trindade et al suggested that the breakdown of osseointegration is dependent on the balance among the immune system and the trilogy of patient characteristics, surgical handling, and implant type. ${ }^{49}$ However, those factors are responsible for bone loss in the initial stages of healing. What happens when MBL starts in the later stage? Several additional parameters have also been recognized as potential triggering factors activating the foreign body response and leading to bone loss. Albrektsson et al described this phenomenon as a "late disbalance of the foreign body equilibrium." Occlusal overloading, cement remnants, and bacteria are among these factors, and they will be analyzed further. ${ }^{54}$

\section{Peri-implantitis as a Disease Entity}

As mentioned earlier, peri-implantitis was introduced as a term to describe the inflammatory process around dental implants in the first European Workshop on Periodontology in 1994. Since then, numerous definitions have been proposed, and Rosen and Clem have identified eight different definitions of peri-implantitis. ${ }^{55}$ The existence of peri-implantitis as a unique disease entity has become a controversy among researchers. Albrektsson expressed the opinion that a chronic inflammation accompanies the foreign body response, and MBL around implants should be considered a result of disruption of the installed equilibrium. ${ }^{14}$ In a subsequent article, a study group of 17 scientists announced the results of the so-called Roma Meeting after critically analyzing the literature on peri-implantitis. In their consensus article, they noted that peri-implantitis prevalence is overestimated based on cross-sectional measurements of bone loss, a fact that leads to overtreatment of the so-called disease. ${ }^{51}$ In addition, they claimed that clinical indices such as bleeding on probing (BoP) and pocket depth (PD) do not have the diagnostic or prognostic accuracy, as in the case of periodontitis. ${ }^{56}$ De Bruyn et al have shown that 19 to $43 \%$ of implants with signs of progressive bone loss did not present PD $>6 \mathrm{~mm}$ or pus on probing. ${ }^{57}$ In addition, BoP was present both in implants with MBL and no loss. ${ }^{58}$ Based on the earlier evidence, the conclusion drawn was that peri-implantitis is not a clearly defined condition. The traditional methods of measuring MBL, PD, and BoP are not adequate diagnostically. Adding to this, Mombelli and Décaillet highlighted the possibility that bacteria, though implicated in bone loss, might not be the primary etiologic agents. ${ }^{37}$ Also, Koka and Zarb proposed that the term "osseoseparation" should describe failing implants rather than "peri-implantitis," which refers to a disease. ${ }^{59}$ The current definition of peri-implantitis in the 2017 World Workshop on Peri-implant diseases and conditions includes the presence of bleeding and/or suppuration on gentle probing and increased probing depth compared with previous examinations and the presence of bone loss beyond any crestal bone level changes resulting from initial bone remodeling. ${ }^{3}$ This means that every implant might be included in the later 
definition since inflammation characterizes every foreign body response.

\section{Further Evidence Suggesting the Existence of a Foreign Body Reaction}

Interesting evidence regarding the concept of FBR has arisen from the histopathology of peri-implant compared with periodontal diseases. As mentioned earlier in this article, both entities share some of the most purulent microbiota; however, differences do exist. Initial animal studies comparing the inflammatory reaction after experimental plaque accumulation in implants and teeth showed that although the response was initially similar, after 90 days, the inflammatory cell infiltrate was higher in the case of implants and was extended to the bone marrow. ${ }^{16,18,60}$ Later human studies proved that in the case of peri-implantitis, the inflammatory infiltrate is greater and consists of higher concentrations of plasma cells, macrophages, and neutrophils. ${ }^{61}$ Similar to periodontitis, the lesions at peri-implantitis sites were also dominated by plasma cells and lymphocytes, ${ }^{62}$ but characterized by more massive proportions of polymorphonuclear leukocytes and macrophages. ${ }^{63}$

In addition, peri-implant bony lesions usually follow a typical crater shape rather than the atypical periodontal bone loss. The crater shape and the lesion's evenness with a well-defined distance of bone resorption from the implant surface suggest that it is not the mere result of a disease, and an FBR has to be implicated. ${ }^{10}$ Becker et al further added this hypothesis by comparing the gene expression in peri-implantitis and periodontal lesions using transcriptomic analysis. They concluded that different RNAs were expressed in the case of periodontitis and peri-implantitis associated with bacterial or immune responses, respectively. ${ }^{64}$

\section{Other Potential Factors Implicated in the Pathogenesis of Peri-implantitis}

Among the potential factors responsible for peri-implantitis initiation, the role of several them has yet to be elucidated.

\section{Titanium Metal Particles}

Titanium is considered an inert metal as an oxygen layer forms on its surface when in contact with biological tissues preventing corrosion. However, no metal or alloy is completely inert in vivo as the release of metal particles occurs after the interaction with interstitial fluids due to electrochemical processes. ${ }^{65}$ Although the titanium oxide layer can reform, the action of continuous wear, exposure to chemicals, bacteria, and their subproducts, and the presence of an acidic environment can degrade the titanium oxide layer. ${ }^{66,67} \mathrm{~A}$ recent systematic review suggested that the release of titanium metal particles may occur in any implant rehabilitation phase, including surgical, prosthetic, and maintenance phase. ${ }^{68}$ Besides, the emission of titanium particles may be induced after titanium surface instrumentation due to the low wear resistance of titanium. ${ }^{69}$ Light microscopic analysis of peri-implant tissue specimens has revealed the presence of titanium particles in almost $90 \%$ of the specimens, in a mixture with a chronic inflammatory infiltrate. ${ }^{70}$ In a series of experimental studies in rats, Olmedo et al proved that titanium particles could be transported through blood and serum and accumulated in the parenchyma of organs such as the liver or spleen. ${ }^{71}$ Besides, increased levels of titanium dioxide were found in macrophages and cells of the mononuclear cell lineage..$^{72}$ There is evidence that titanium leaked ions may emit from metal surfaces and induce osteoclastic activity, changes in RNA and DNA structures of adjacent cells (fibroblasts and gingival epithelium cells) even immune damage. ${ }^{73}$ Studies on metal particle release from dental implants on human biopsies have revealed titanium particles in the inflammatory infiltrate adjacent to peri-implantitis lesions..$^{74,75}$ In addition, the quantity of those ions seems to be more significant in the case of peri-implant lesions compared with healthy peri-implant sites. ${ }^{76}$ In vitro studies have shown evidence of enhancement of the inflammatory response from titanium ions, as suggested by the increase of proinflammatory factors such as tumor necrosis factor- $\alpha$ (TNF- $\alpha$ ) and interleukin (IL)- $1 \beta$ after the metal ion challenge. ${ }^{77-79}$ When the concept of FBR is considered, titanium metal particles are thought to activate the immune response disrupting the delicate balance among osteoblasts and osteoclasts, leading to bone loss. ${ }^{54}$ Alrabeah et al in an in vivo study found that titanium products may affect bone-resorbing regulators such as receptor activator of nuclear factor kappa-B ligand (RANKL), regulating osteoblastic cell viability and apoptosis. ${ }^{80}$ However, the exact role of titanium metal particles has yet to be elucidated, and there is not adequate evidence for their involvement in peri-implantitis pathogenesis. ${ }^{11,81}$

\section{Occlusal Overload}

The research on the potential effect of traumatic occlusal forces on peri-implant MBL has yielded contradictory results. One of the first reports on occlusal overload came from Isidor's study group in an animal model..$^{82}$ In their study, the influence of either occlusal overload or plaque accumulation on MBL was examined. None of the implants with plaque accumulation experienced MBL, while in the occlusal overloading group, loss of osseointegration was observed after 4 and 5 months. ${ }^{82}$ Similar results were reported by later studies. ${ }^{83,84}$

In contrast, in the report by Gotfredsen et al, mucositis and experimental peri-implantitis implants were subjected to a lateral static load by expansion screws. They indicated no discrepancy between loaded and unloaded implants in terms of MBL, and the lateral load did not cause bone loss at mucositis implants. ${ }^{85}$ Later, Heitz-Mayfield et al evaluated the effect of supraocclusal contacts on implants placed in dogs. After 8 months, no difference in marginal bone response was noted. ${ }^{86}$ Although the earlier experiments differ in methodology and the condition of occlusal overload is not clearly defined, a distinct conclusion is difficult to be drawn. Recent evidence suggests that the force's magnitude may influence the marginal bone response with higher magnitude forces resulting in MBL. However, there is still a lack of well-designed randomized controlled 
clinical trials, and there is still no evidence that occlusal overload would influence the initiation or progression of peri-implantitis.

\section{Genetic Predisposition}

A significant observation about implant failures is that usually, a small number of patients lose many implants. This clusterization phenomenon has been identified in many studies. ${ }^{87,88}$ Weyant et al examined the survival rate of implants in 598 patients and noticed that more than half of the cases that received multiple implants had more than one failure. They estimated that patients who had one implant lost were 1.3 more likely to lose more implants. ${ }^{89}$ These findings led to the hypothesis that host factors affect implant survival, and therefore, genetic predisposition may play an essential role in the development of peri-implantitis. A large number of gene polymorphisms have been evaluated. Initially, most of the studies referred to polymorphisms of cytokines which play a vital role in the immune response, ${ }^{90-92}$ such as the IL- $1 \mathrm{a}, \mathrm{IL}-1 \beta$, and their antagonist protein IL-1ra, IL-6, IL-10, IL-17, TNF- $\alpha$, and transforming growth factor- $\beta 1$. Apart from these, various other genes have been investigated, for example, genes encoding CD14, RANKL, microRNAs, bone morphogenetic proteins, fibroblast growth factor, TNF receptor-associated factor family member-associated NF-kappa- $\beta$ activator (TANK), serine/threonine-protein kinase B-Raf (BRAF), calcitonin receptor, and haptoglobin. There are many discrepancies in the results of the above-mentioned studies. Some succeeded to detect possible associations and others not. For instance, Laine et al in their study found no association between peri-implantitis and IL- $1 \alpha$ and IL- $1 \beta$ genotypes or their combination (single nucleotide polymorphisms at positions IL- $1 \alpha-889$ and IL- $1 \beta+3954) .{ }^{90}$

In contrast, in their case-control study, Hamdy and Ebrahem stated that individuals carrying the IL- $1 \alpha-889$ and IL- $1 \beta+3954$ allele two genotypes were at higher risk for increased peri-implant tissue destruction. ${ }^{93}$ Recent gene analysis studies suggest the participation of the nucleotide oligomerization domainlike receptor signaling pathway and the proteasome pathway and its subunits genes ${ }^{94}$ or the expression of a fibro-osteoclastic cell lineage in the peri-implantitis lesion. ${ }^{95}$ In addition, recent transcriptomic data indicate the upregulation of the cyclooxygenase-2 pathway in the case of peri-implantitis. ${ }^{96}$

Recent reviews concluded that the correlation of peri-implantitis risk and investigated genetic polymorphisms cannot be supported by the current literature. ${ }^{97-99}$ In addition, the consensus report of the FDI World Dental Federation regarding genetic and acquired risk factors of peri-implant diseases also stated that no decisive conclusions could be drawn about the genetic susceptibility in peri-implantitis. ${ }^{92}$ More well-designed studies are needed to detect genes responsible for the increased risk of development of peri-implant diseases. This will play a key role in the treatment of these patients and the detection of proper candidates for implant therapy.

\section{Excess Cement}

There is evidence of a correlation among cement remnants and peri-implant inflammation in cement-retained restorations. ${ }^{100-103}$ The rationale is that the rough surface of the cement may encourage biofilm adhesion. Advocates of the foreign body response suggest that cement excess may act as a second foreign body leading to the disbalance of the established equilibrium. ${ }^{54}$ Wilson reported that $81 \%$ of peri-implantitis cases were associated with excess cement. ${ }^{100}$ There is, however, significant variability in the prevalence of implants with excess cement that are affected by peri-implantitis. ${ }^{104}$ Nonetheless, not all the implants with cement remnants suffer from peri-implantitis. ${ }^{102}$ Also, there is no difference in the prevalence of peri-implantitis among screw and cement-retained restorations. ${ }^{105,106}$ Evidence suggests that the use of zinc-containing cements results in less inflammation provocation due to the material's solubility. ${ }^{107}$ Whatever the exact role of cement remnants is, their removal results in the resolution of inflammation and healing of the peri-implant lesion. ${ }^{100}$

\section{Conclusion}

The current concepts on the pathogenesis of peri-implantitis focus on several parameters, which include the microbial factor, the genetic predisposition of each individual to develop peri-implant disease, the role of traumatic occlusal forces, the importance of titanium particles diffused in the adjacent tissues, and the biological reaction that they could initiate and the presence of excess cement after prosthetic installation. Microbiological evidence mainly demonstrates that certain consensus periodontal pathogens are implicated in peri-implant lesions; however, the participation of a distinct microflora consists of opportunistic microorganisms or uncultivable species in specific peri-implantitis cases is also suggested and requires further investigation. Each individual's genetic traits, especially with newer "shotgun" technologies, could offer a unique insight into peri-implant pathology in the future, assisting in identifying subjects not suitable for implant therapy or at risk of developing periimplantitis. Traumatic occlusal load and the presence of excess cement appear to be contributing factors in the initiation and progression of peri-implant inflammation, although data are often contradictory. According to the existing literature, the presence of titanium particles and the release of titanium ions also appear to possess the ability to provoke biological reactions related to tissue inflammation. Finally, a line of evidence supports the idea that osseointegration results from foreign body response. The tissues aim to embed the titanium material in the bone as a mode of protection for adjacent tissues peri-implant health occurs if an equilibrium with the immune response is established. When this equilibrium is disturbed, peri-implantitis occurs, and therefore, peri-implantitis is not a clearly defined bacterial-caused disease. 
Taken collectively, current evidence does not allow for the extraction of robust conclusions. More studies with advanced technologies are required to identify the exact mechanisms of peri-implant pathology to achieve successful prevention and effective cause-related therapy.

\section{Availability of Data and Materials}

All data generated or analyzed during this study are included in this published article.

\section{Consent for Publication}

Written informed consent was obtained from the patient for publication of these images.

\section{Authors' Contributions}

All the authors were involved with the literature review. All the authors read and approved the final manuscript.

\section{Funding}

None.

\section{Conflict of Interest}

None declared.

\section{References}

1 Zitzmann NU, Berglundh T. Definition and prevalence of peri-implant diseases. J Clin Periodontol 2008;35(8, Suppl):286-291

2 Tallarico M, Canullo L, Wang H-L, Cochran DL, Meloni SM. Classification Systems for peri-implantitis: a narrative review with a proposal of a new evidence-based etiology codification. Int J Oral Maxillofac Implants 2018;33(4):871-879

3 Berglundh T, Armitage G, Araujo MG, et al. Peri-implant diseases and conditions: Consensus report of workgroup 4 of the 2017 World Workshop on the Classification of Periodontal and Peri-Implant Diseases and Conditions. J Clin Periodontol 2018;45 (Suppl 20):S286-S291

4 Mombelli A, Müller N, Cionca N. The epidemiology of peri-implantitis.ClinOral ImplantsRes2012;23(Suppl6):67-76

5 Elemek E, Agrali OB, Kuru B, Kuru L. Peri-implantitis and severity level. Eur J Dent 2020;14(1):24-30

6 Poli PP, Cicciu M, Beretta M, Maiorana C. Peri-implant mucositis and peri-implantitis: a current understanding of their diagnosis, clinical implications, and a report of treatment using a combined therapy approach. J Oral Implantol 2017;43(1):45-50

7 Cosgarea R, Sculean A, Shibli JA, Salvi GE. Prevalence of periimplant diseases - a critical review on the current evidence. Braz Oral Res 2019;33(suppl 1):e063

8 Klinge B, Meyle J; Working Group 2. Peri-implant tissue destruction. The Third EAO Consensus Conference 2012. Clin Oral Implants Res 2012;23, Suppl 6):108-110

9 Daugela P, Cicciù M, Saulacic N. Surgical regenerative treatments for peri-implantitis: meta-analysis of recent findings in a systematic literature review. J Oral Maxillofac Res 2016;7(3):e15

10 Marcantonio Junior E, Romito GA, Shibli JA. Peri-implantitis as a "burden" disease. Braz Oral Res 2019;33(1, suppl 1):e087

11 Schwarz F, Derks J, Monje A, Wang HL. Peri-implantitis. J Clin Periodontol 2018;45(45, suppl 20):S246-S266

12 Mombelli A, van Oosten MAC, Schürch E Jr, Land NP. The microbiota associated with successful or failing osseointegrated titanium implants. Oral Microbiol Immunol 1987;2(4): 145-151
13 Passariello C, Di Nardo D, Testarelli L. Inflammatory periimplant diseases and the periodontal connection question. Eur J Dent 2019;13(1):119-123

14 Albrektsson T, Dahlin C, Jemt T, Sennerby L, Turri A, Wennerberg A. Is marginal bone loss around oral implants the result of a provoked foreign body reaction? Clin Implant Dent Relat Res 2014;16(2):155-165

15 Belibasakis GN, Charalampakis G, Bostanci N, Stadlinger B. Peri-implant infections of oral biofilm etiology. Adv Exp Med Biol 2015;830:69-84

16 Ericsson I, Berglundh T, Marinello C, Liljenberg B, Lindhe J. Long-standing plaque and gingivitis at implants and teeth in the dog. Clin Oral Implants Res 1992;3(3):99-103

17 Zitzmann NU, Abrahamsson I, Berglundh T, Lindhe J. Soft tissue reactions to plaque formation at implant abutments with different surface topography. An experimental study in dogs. J Clin Periodontol 2002;29(5):456-461

18 Berglundh T, Lindhe J, Marinello C, Ericsson I, Liljenberg B. Soft tissue reaction to de novo plaque formation on implants and teeth. An experimental study in the dog. Clin Oral Implants Res 1992;3(1):1-8

19 Ericsson I, Persson LG, Berglundh T, Marinello CP, LindheJ, Klinge B. Different types of inflammatory reactions in peri-implant soft tissues. J Clin Periodontol 1995;22(3):255-261

20 Pontoriero R, Tonelli MP, Carnevale G, Mombelli A, Nyman SR, Lang NP. Experimentally induced peri-implant mucositis. A clinical study in humans. Clin Oral Implants Res 1994;5(4):254-259

21 Heitz-Mayfield LJA, Lang NP. Comparative biology of chronic and aggressive periodontitis vs. peri-implantitis. Periodontol 2000 2010;53(1):167-181

22 Edgerton M, Lo SE, Scannapieco FA. Experimental salivary pellicles formed on titanium surfaces mediate adhesion of streptococci. Int J Oral Maxillofac Implants 1996;11(4):443-449

23 Lang NP, Berglundh T; Working Group 4 of Seventh European Workshop on Periodontology. Periimplant diseases: where are we now?-Consensus of the Seventh European Workshop on Periodontology. J Clin Periodontol 2011;38(Suppl 11):178-181

24 Apse P, Ellen RP, Overall CM, Zarb GA. Microbiota and crevicular fluid collagenase activity in the osseointegrated dental implant sulcus: a comparison of sites in edentulous and partially edentulous patients. J Periodontal Res 1989;24(2):96-105

25 Rams TE, Roberts TW, Tatum H Jr, Keyes PH. The subgingival microbial flora associated with human dental implants. J Prosthet Dent 1984;51(4):529-534

26 Hultin M, Gustafsson A, Hallström H, Johansson LÅ, Ekfeldt A, Klinge B. Microbiological findings and host response in patients with peri-implantitis. Clin Oral Implants Res 2002;13(4):349-358

27 Rosenberg ES, Torosian JP, Slots J. Microbial differences in 2 clinically distinct types of failures of osseointegrated implants. Clin Oral Implants Res 1991;2(3):135-144

28 Alcoforado GA, Rams TE, Feik D, Slots J. Microbial aspects of failing osseointegrated dental implants in humans. J Parodontol 1991;10(1):11-18

29 Botero JE, González AM, Mercado RA, Olave G, Contreras A. Subgingival microbiota in peri-implant mucosa lesions and adjacent teeth in partially edentulous patients. J Periodontol 2005;76(9):1490-1495

30 Leonhardt A, Renvert S, Dahlén G. Microbial findings at failing implants. Clin Oral Implants Res 1999;10(5):339-345

31 Koyanagi T, Sakamoto M, Takeuchi Y, Ohkuma M, Izumi Y. Analysis of microbiota associated with peri-implantitis using 16S rRNA gene clone library. J Oral Microbiol 2010;2:2

32 Kumar PS, Mason MR, Brooker MR, O’Brien K. Pyrosequencing reveals unique microbial signatures associated with healthy and failing dental implants. J Clin Periodontol 2012;39(5):425-433 
33 Albertini M, López-Cerero L, O'Sullivan MG, et al. Assessment of periodontal and opportunistic flora in patients with peri-implantitis. Clin Oral Implants Res 2015;26(8):937-941

34 Dabdoub SM, Tsigarida AA, Kumar PS. Patient-specific analysis of periodontal and peri-implant microbiomes. J Dent Res 2013;92(12, Suppl):168S-175S

35 Yeh HC, Lu JJ, Chang SC, Ge MC. Identification of microbiota in peri-implantitis pockets by matrix-assisted laser desorption/ionization time-of-flight mass spectrometry. Sci Rep 2019;9(1):774

36 Charalampakis G, Belibasakis GN. Microbiome of peri-implant infections: lessons from conventional, molecular and metagenomic analyses. Virulence 2015;6(3):183-187

37 Mombelli A, Décaillet F. The characteristics of biofilms in peri-implant disease. J Clin Periodontol 2011;38(Suppl 11) :203-213

38 Rakic M, Grusovin MG, Canullo L. The microbiologic profile associated with peri-implantitis in humans: a systematic review. Int J Oral Maxillofac Implants 2016;31(2):359-368

39 Persson GR, Renvert S. Cluster of bacteria associated with peri-implantitis. Clin Implant Dent Relat Res 2014;16(6):783-793

40 Lafaurie GI, Sabogal MA, Castillo DM, et al. Microbiome and microbial biofilm profiles of peri-implantitis: a systematic review. J Periodontol 2017;88(10):1066-1089

41 Padial-Molina M, López-Martínez J, O’Valle F, Galindo-Moreno P. Microbial profiles and detection techniques in peri-implant diseases: a systematic review. J Oral Maxillofac Res 2016;7(3):e10

42 Pérez-Chaparro PJ, Duarte PM, Shibli JA, et al. The current weight of evidence of the microbiologic profile associated with peri-implantitis: a systematic review. J Periodontol 2016;87(11):1295-1304

43 Retamal-Valdes B, Formiga MC, Almeida ML, et al. Does subgingival bacterial colonization differ between implants and teeth? A systematic review. Braz Oral Res 2019;33(suppl 1): e064

44 Brånemark PI, Hansson BO, Adell R, et al. Osseointegrated implants in the treatment of the edentulous jaw. Experience from a 10-year period. Scand J Plast Reconstr Surg Suppl 1977;16:1-132

45 Schroeder A, Pohler O, Sutter F. Tissue reaction to an implant of a titanium hollow cylinder with a titanium surface spray layer. SSO Schweiz Monatsschr Zahnheilkd 1976;86(7): 713-727 (German)

46 Donath K. Pathogenesis of bony pocket formation around dental implants. J Dent Assoc S Afr 1992;47(5):204-208

47 Donath K, Laass M, Günzl HJ. The histopathology of different foreign-body reactions in oral soft tissue and bone tissue. Virchows Arch A Pathol Anat Histopathol 1992;420(2):131-137

48 Albrektsson $\mathrm{T}$, Wennerberg A. On osseointegration in relation to implant surfaces. Clin Implant Dent Relat Res 2019;21(Suppl 1) :4-7

49 Trindade R, Albrektsson T, Tengvall P, Wennerberg A. Foreign body reaction to biomaterials: on mechanisms for buildup and breakdown of osseointegration. Clin Implant Dent Relat Res 2016;18(1):192-203

50 Trindade R, Albrektsson T, Wennerberg A. Current concepts for the biological basis of dental implants: foreign body equilibrium and osseointegration dynamics. Oral Maxillofac Surg Clin North Am 2015;27(2):175-183

51 Chappuis V, Cavusoglu Y, Gruber R, Kuchler U, Buser D, Bosshardt DD. Osseointegration of zirconia in the presence of multinucleated giant cells. Clin Implant Dent Relat Res 2016;18(4):686-698

52 Trindade R, Albrektsson T, Galli S, Prgomet Z, Tengvall P, Wennerberg A. Osseointegration and foreign body reaction: titanium implants activate the immune system and suppress bone resorption during the first 4 weeks after implantation. Clin Implant Dent Relat Res 2018;20(1):82-91

53 Albrektsson T, Jemt T, Mölne J, Tengvall P, Wennerberg A. On inflammation-immunological balance theory-A critical apprehension of disease concepts around implants: mucositis and marginal bone loss may represent normal conditions and not necessarily a state of disease. Clin Implant Dent Relat Res 2019;21(1):183-189

54 Albrektsson T, Canullo L, Cochran D, De Bruyn H. "Peri-implantitis": a complication of a foreign body or a manmade "disease". Facts and fiction. Clin Implant Dent Relat Res 2016;18(4):840-849

55 Academy Report: Peri-Implant Mucositis and Peri-Implantitis: A Current Understanding of Their Diagnoses and Clinical Implications. Journal of Periodontology, 84: 436-443

56 Coli P, Christiaens V, Sennerby L, Bruyn H. Reliability of periodontal diagnostic tools for monitoring peri-implant health and disease. Periodontol 2000 2017;73(1):203-217

57 De Bruyn H, Christiaens V, Doornewaard R, et al. Implant surface roughness and patient factors on long-term peri-implant bone loss. Periodontol 2000 2017;73(1):218-227

58 Albrektsson T, Chrcanovic B, Östman P-O, Sennerby L. Initial and long-term crestal bone responses to modern dental implants. Periodontol 2000 2017;73(1):41-50

59 Koka S, Zarb G. On osseointegration: the healing adaptation principle in the context of osseosufficiency, osseoseparation, and dental implant failure. Int J Prosthodont 2012;25(1):48-52

60 Lindhe J, Berglundh T, Ericsson I, Liljenberg B, Marinello C. Experimental breakdown of peri-implant and periodontal tissues. A study in the beagle dog. Clin Oral Implants Res 1992;3(1):9-16

61 Carcuac O, Berglundh T. Composition of human peri-implantitis and periodontitis lesions. J Dent Res 2014;93(11):1083-1088

62 Gualini F, Berglundh T. Immunohistochemical characteristics of inflammatory lesions at implants. J Clin Periodontol 2003;30(1):14-18

63 Berglundh T, Zitzmann NU, Donati M. Are peri-implantitis lesions different from periodontitis lesions? J Clin Periodontol 2011;38(Suppl 11) :188-202

64 Becker ST, Beck-Broichsitter BE, Graetz C, Dörfer CE, Wiltfang J, Häsler R. Peri-implantitis versus periodontitis: functional differences indicated by transcriptome profiling. Clin Implant Dent Relat Res 2014;16(3):401-411

65 Noumbissi S, Scarano A, Gupta S. A literature review study on atomic ions dissolution of titanium and its alloys in implant dentistry. Materials (Basel) 2019;12(3):1-15

66 Bianco PD, Ducheyne P, Cuckler JM. Titanium serum and urine levels in rabbits with a titanium implant in the absence of wear. Biomaterials 1996;17(20):1937-1942

67 Addison O, Davenport AJ, Newport RJ, et al. Do 'passive' medical titanium surfaces deteriorate in service in the absence of wear? J R Soc Interface 2012;9(76):3161-3164

68 Delgado-Ruiz R, Romanos G. Potential causes of titanium particle and ion release in implant dentistry: a systematic review. Int J Mol Sci 2018;19(11):E3585

69 Valderrama P, Blansett JA, Gonzalez MG, Cantu MG, Wilson TG. Detoxification of implant surfaces affected by peri-implant disease: an overview of non-surgical methods. Open Dent J 2014;8:77-84

70 Berryman Z, Bridger L, Hussaini HM, Rich AM, Atieh M, Tawse-Smith A. Titanium particles: an emerging risk factor for peri-implant bone loss. Saudi Dent J 2020;32(6):283-292

71 Olmedo DG, Tasat DR, Evelson P, Guglielmotti MB, Cabrini RL. Biological response of tissues with macrophagic activity to titanium dioxide.J Biomed Mater Res A 2008;84(4):1087-1093

72 Olmedo DG, Duffó G, Cabrini RL, Guglielmotti MB. Local effect of titanium implant corrosion: an experimental study in rats. Int J Oral Maxillofac Surg 2008;37(11):1032-1038 
73 Vasconcelos DM, Santos SG, Lamghari M, Barbosa MA. The two faces of metal ions: from implants rejection to tissue repair/ regeneration. Biomaterials 2016;84:262-275

74 Fretwurst T, Buzanich G, Nahles S, Woelber JP, Riesemeier H, Nelson K. Metal elements in tissue with dental peri-implantitis: a pilot study. Clin Oral Implants Res 2016;27(9):1178-1186

75 Wilson TG Jr, Valderrama P, Burbano M, et al. Foreign bodies associated with peri-implantitis human biopsies. J Periodontol 2015;86(1):9-15

76 Olmedo DG, Nalli G, Verdú S, Paparella ML, Cabrini RL. Exfoliative cytology and titanium dental implants: a pilot study. J Periodontol 2013;84(1):78-83

77 Irshad M, Scheres N, Crielaard W, Loos BG, Wismeijer D, Laine ML. Influence of titanium on in vitro fibroblast-Porphyromonas gingivalis interaction in peri-implantitis. J Clin Periodontol 2013;40(9):841-849

78 Pettersson M, Kelk P, Belibasakis GN, Bylund D, Molin Thorén M, Johansson A. Titanium ions form particles that activate and execute interleukin-1Brelease from lipopolysaccharide-primed macrophages. J Periodontal Res 2017; 52(1):21-32

79 Taira M, Sasaki K, Saitoh S, et al. Accumulation of element Ti in macrophage-like RAW264 cells cultured in medium with $1 \mathrm{ppm}$ Ti and effects on cell viability, SOD production and TNF-alpha secretion. Dent Mater J 2006;25(4):726-732

80 Alrabeah GO, Brett P, Knowles JC, Petridis H. The effect of metal ions released from different dental implant-abutment couples on osteoblast function and secretion of bone resorbing mediators. J Dent 2017;66(March):91-101

81 Corrêa MG, Pimentel SP, Ribeiro FV, Cirano FR, Casati MZ. Host response and peri-implantitis. Braz Oral Res 2019; 33(suppl 1):e066

82 Isidor F. Loss of osseointegration caused by occlusal load of oral implants. A clinical and radiographic study in monkeys. Clin Oral Implants Res 1996;7(2):143-152

83 Esaki D, Matsushita Y, Ayukawa Y, Sakai N, Sawae Y, Koyano K. Relationship between magnitude of immediate loading and peri-implant osteogenesis in dogs. Clin Oral Implants Res 2012;23(11):1290-1296

84 Miyata T, Kobayashi Y, Araki H, Ohto T, Shin K. The influence of controlled occlusal overload on peri-implant tissue. Part 3: a histologic study in monkeys. Int J Oral Maxillofac Implants 2000;15(3):425-431

85 Gotfredsen K, Berglundh T, Lindhe J. Bone reactions at implants subjected to experimental peri-implantitis and static load. A study in the dog. J Clin Periodontol 2002;29(2):144-151

86 Heitz-Mayfield LJ, Schmid B, Weigel C, et al. Does excessive occlusal load affect osseointegration? An experimental study in the dog. Clin Oral Implants Res 2004;15(3):259-268

87 Tonetti MS. Determination of the success and failure of root-form osseointegrated dental implants. Adv Dent Res 1999;13:173-180

88 Fransson C, Lekholm U, Jemt T, Berglundh T. Prevalence of subjects with progressive bone loss at implants. Clin Oral Implants Res 2005;16(4):440-446

89 Weyant RJ, Burt BA, Weyant RJ, Burt BA. An assessment of survival rates and within-patient clustering of failures for endosseous oral implants. J Dent Res 1993;72(1):2-8

90 Laine ML, Crielaard W, Loos BG. Genetic susceptibility to periodontitis. Periodontol 2000 2012;58(1):37-68

91 Melo RF, Lopes BMV, Shibli JA, Marcantonio E Jr, Marcantonio RAC, Galli GMT. Interleukin-1ßand interleukin-6 expression and gene polymorphisms in subjects with peri-implant disease. Clin Implant Dent Relat Res 2012;14(6): 905-914

92 Meyle J, Casado P, Fourmousis I, Kumar P, Quirynen M, Salvi GE. General genetic and acquired risk factors, and prevalence of peri-implant diseases - consensus report of working group 1. Int Dent J 2019;69(Suppl 2):3-6

93 Hamdy AAE-MM, Ebrahem MAE-M. The effect of interleukin- 1 allele 2 genotype (IL-1a(-889) and IL-1b(+3954)) on the individual's susceptibility to peri-implantitis: case-control study. J Oral Implantol 2011;37(3):325-334

94 Zhang H, Zhang X, Huang J, Fan X. Identification of key genes and pathways for peri-implantitis through the analysis of gene expression data. Exp Ther Med 2017;13(5):1832-1840

95 Schminke B, Vom Orde F, Gruber R, Schliephake H, Bürgers R, Miosge N. The pathology of bone tissue during peri-implantitis. J Dent Res 2015;94(2):354-361

96 Liu Y, Liu Q, Li Z, et al. Long non-coding RNA and mRNA expression profiles in peri-implantitis vs periodontitis. J Periodontal Res 2020;55(3):342-353

97 Dereka X, Mardas N, Chin S, Petrie A, Donos N. A systematic review on the association between genetic predisposition and dental implant biological complications. Clin Oral Implants Res 2012;23(7):775-788

98 Fourmousis I, Vlachos M. Genetic risk factors for the development of periimplantitis. Implant Dent 2019;28(2):103-114

99 Chen X, Zhao Y. Genetic involvement in dental implant failure: association with polymorphisms of genes modulating inflammatory responses and bone metabolism. J Oral Implantol 2019;45(4):318-326

100 Wilson TG Jr. The positive relationship between excess cement and peri-implant disease: a prospective clinical endoscopic study. J Periodontol 2009;80(9):1388-1392

101 Korsch M, Walther W, Bartols A. Cement-associated peri-implant mucositis. A 1-year follow-up after excess cement removal on the peri-implant tissue of dental implants. Clin Implant Dent Relat Res 2017;19(3):523-529

102 Korsch M, Walther W. Peri-implantitis associated with type of cement: a retrospective analysis of different types of cement and their clinical correlation to the peri-implant tissue. Clin Implant Dent Relat Res 2015;17(Suppl 2):e434-e443

103 Korsch M, Obst U, Walther W. Cement-associated peri-implantitis: a retrospective clinical observational study of fixed implant-supported restorations using a methacrylate cement. Clin Oral Implants Res 2014;25(7):797-802

104 Linkevicius T, Vindasiute E, Puisys A, Linkeviciene L, Maslova N, Puriene A. The influence of the cementation margin position on the amount of undetected cement. A prospective clinical study. Clin Oral Implants Res 2013;24(1):71-76

105 Daubert DM, Weinstein BF, Bordin S, Leroux BG, Flemming TF. Prevalence and predictive factors for peri-implant disease and implant failure: a cross-sectional analysis. J Periodontol 2015;86(3):337-347

106 Kotsakis GA, Zhang L, Gaillard P, Raedel M, Walter MH, Konstantinidis IK. Investigation of the association between cement retention and prevalent peri-implant diseases: a cross-sectional study. J Periodontol 2016;87(3):212-220

107 Yanikoğlu N, Yeşil Duymuş Z. Evaluation of the solubility of dental cements in artificial saliva of different $\mathrm{pH}$ values. Dent Mater J 2007;26(1):62-67 